\title{
A vitamin K-dependent carboxylase orthologue is involved in antibiotic biosynthesis
}

DOI:

10.1038/s41929-018-0178-2

\section{Document Version}

Accepted author manuscript

Link to publication record in Manchester Research Explorer

\section{Citation for published version (APA):}

Law, B., Zhuo, Y., Winn, M., Francis, D., Zhang, Y., Samborskyy, M., Murphy, A., Ren, L., Leadlay, P. F., \& Micklefield, J. (2018). A vitamin K-dependent carboxylase orthologue is involved in antibiotic biosynthesis. Nature Catalysis, 1, 977-984. https://doi.org/10.1038/s41929-018-0178-2

\section{Published in:}

Nature Catalysis

\section{Citing this paper}

Please note that where the full-text provided on Manchester Research Explorer is the Author Accepted Manuscript or Proof version this may differ from the final Published version. If citing, it is advised that you check and use the publisher's definitive version.

\section{General rights}

Copyright and moral rights for the publications made accessible in the Research Explorer are retained by the authors and/or other copyright owners and it is a condition of accessing publications that users recognise and abide by the legal requirements associated with these rights.

\section{Takedown policy}

If you believe that this document breaches copyright please refer to the University of Manchester's Takedown Procedures [http://man.ac.uk/04Y6Bo] or contact uml.scholarlycommunications@manchester.ac.uk providing relevant details, so we can investigate your claim.

\section{OPEN ACCESS}




\title{
A vitamin $\mathrm{K}$-dependent carboxylase orthologue is involved in antibiotic biosynthesis
}

\author{
Brian J. C. Law ${ }^{1,3}$, Ying Zhuo ${ }^{1,3}$, Michael Winn', Daniel Francis', Yingxin Zhang', Markiyan Samborskyy ${ }^{2}$,

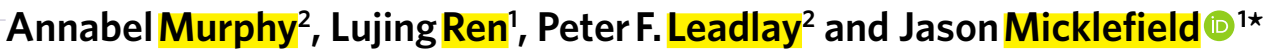

\begin{abstract}
Vitamin K-dependent carboxylase (VKDC) enzymes modify glutamate residues in mammalian vitamin K-dependent proteins, generating $\gamma$-carboxyglutamatic acids with malonate moieties that mediate important physiological responses such as blood coagulation. Proteins with sequence similarity to mammalian VKDC are also found in bacteria; however, their function remains unknown. The antibiotic malonomycin from Streptomyces rimosus contains an unusual malonate group, of unknown origin, that is essential for its biological activity. Here, we show that a bacterial VKDC orthologue (MloH) is responsible for the malonic acid moiety in malonomycin. Using clustered regularly interspaced short palindromic repeats (CRISPR)-CRISPR-associated protein 9 gene editing, complementation and mutagenesis experiments, this VKDC-like enzyme was shown to $\alpha$-carboxylate an aspartyl residue within a hybrid polyketide-non-ribosomal peptide intermediate during malonomycin biosynthesis. This study reveals a highly unusual biosynthetic pathway to malonic acid-containing metabolites, providing a functional role for VKDC-like proteins in prokaryotes and a vitamin K-dependent carboxylation reaction with a non-proteinogenic substrate.
\end{abstract}

M alonomycin (antibiotic K16) 1 (Fig. 1a) is a secondary metabolite with antiprotozoal and antifungal activity, isolated from Streptomyces rimosus paromomycinus ${ }^{1}$. Malonomycin is the only known bacterial natural product with an intact aminomalonic acid moiety. While the structure of malonomycin was established some time ago, with L-Ser and L-diaminopropionate (L-Dap) as probable precursors ${ }^{1-3}$, the biosynthetic pathway, including the origin of the unique aminomalonate unit, has remained unexplained. Malonates are key precursors in the biosynthesis of fatty acids and polyketides (Fig. 1b), and are produced by either biotin-dependent acetyl-CoA carboxylases, crotonyl-CoA carboxylase/reductase enzymes or oxidation of glyceryl/serinyl-acyl carrier protein precursors to hydroxy/aminomalonyl-acyl carrier protein thioesters in polyketide synthase (PKS) assembly lines. ${ }^{4}$ In these examples, decarboxylation of the malonyl thioester intermediates provides the thermodynamic driving force for subsequent carbon-carbon bond formation. It is difficult to envisage how this

Q1 $\mathbf{Q}^{2}$ common biosynthetic logic could account for the aminomalonate 25 moiety of malonomycin.

Another metabolite possessing an intact malonic acid moiety is $\gamma$-carboxyglutamic acid, derived from carboxylation of Glu residues in vitamin $\mathrm{K}$-dependent (VKD) proteins $^{5-8}$ (Fig. 1c). The mammalian VKD carboxylase (VKDC), catalysing this transformation, is suggested to deprotonate and oxidize the vitamin $\mathrm{K}$ hydroquinone $\left(\mathrm{KH}_{2}\right)$ co-factor, driving the formation of a strong base $\left(\mathrm{K}^{-}\right)^{9-11}$ that deprotonates the non-acidic $\gamma$-methylene group of Glu, which then attacks $\mathrm{CO}_{2}$ to give $\gamma$-carboxyglutamic acid (Fig. 1c). The resulting vitamin $\mathrm{K}$ epoxide $(\mathrm{KO})$ is recycled back to $\mathrm{KH}_{2}$ by the $\mathrm{KO}$ reductase enzyme - the target of clinically important anticoagulant drugs including warfarin ${ }^{12,13}$. Proteins with sequence similarity to the mammalian VKDC are found within other domains of life, including bacteria. For example, a Leptospira VKDC orthologue was shown to convert $\mathrm{KH}_{2}$ to $\mathrm{KO}$, but no carboxylation activity was observed $^{14}$. The function of this and other putative bacterial VKDC remains unknown.
Here, we describe the discovery of a highly unusual biosynthetic pathway to the antibiotic malonomycin. We identified the malonomycin (mlo) biosynthetic gene cluster (BGC) in two S. rimosus strains. Using a combination of bioinformatics, gene editing, complementation and in vitro experiments, we show that a hybrid non-ribosomal peptide synthetase (NRPS)-PKS assembly line generates a precursor premalonomycin, possessing an aspartyl residue that is carboxylated by a bacterial VKDC orthologue $(\mathrm{MloH})$, generating the malonic acid moiety of malonomycin. VKDC-like enzymes are shown to be present in other bacterial species, opening the way for the discovery of new carboxylase enzymes and metabolites containing malonic acid.

\section{Results}

Identification and analysis of the mlo BGC. First, we sequenced the genomes of two S. rimosus strains, paromomycinus NRRL 2455 and paramyceticus R2374, and located two almost identical BGCs containing the genes $m l o F$ and $m l o G$, encoding proteins with similarity to SbnA and SbnB known to transform L-Ser into L-Dap ${ }^{15}$ a precursor of the malonomycin 1 tetramic acid group ${ }^{3}$. The $m l o$ BGC (Fig. 2a and Supplementary Tables 1 and 2) possesses a gene mloI, encoding a dual-module NRPS. The first adenylation $\left(\mathrm{A}_{1}\right)$ domain of MloI is predicted to activate L-Ser, but bioinformatics tools fail to predict the specificity of the second adenylation domain $\left(\mathrm{A}_{2}\right)$. We propose that MloI $\mathrm{A}_{2}$ activates L-Asp via the side-chain carboxyl group to generate the Ser-Asp dipeptide 2 (Fig. 2b). A hybrid PKS-NRPS MloJ is then proposed to introduce malonylCoA to give the $\beta$-keto thioester 3 . The MloJ adenylation domain is predicted to activate L-Dap, which on condensation with $\mathbf{3}$ would generate $\beta$-ketoacyl-Dap thioester 4 . Dieckmann cyclization and chain release would afford the tetramic acid-containing precursor 5 (premalonomycin). Finally, $\alpha$-carboxylation of the aspartyl moiety of 5 would generate $\mathbf{1}$. Analysis revealed $\mathrm{mloH}$, encoding a putative VKDC-like enzyme, as a candidate for this challenging carboxylation (Supplementary Table 1). MloH exhibits low but significant similarity (23\% identity and $38 \%$ similarity) to the human

${ }^{1}$ School of Chemistry and Manchester Institute of Biotechnology, The University of Manchester, Manchester, UK. ${ }^{2}$ Department of Biochemistry, University of Cambridge, Cambridge, UK. ${ }^{3}$ These authors contributed equally: Brian J. C. Law, Ying Zhuo. *e-mail: Jason.micklefield@manchester.ac.uk 
a<smiles>NCC1NC(=O)C(C(=O)CC(NC(=O)[C@H](N)CO)(C(=O)O)C(=O)O)=C1O</smiles>

b

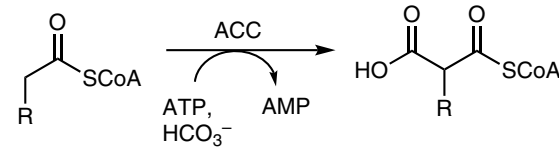<smiles>[2H]C=CC(=O)[Se][N+](=O)[O-]</smiles>
$\mathrm{CO}_{2}$

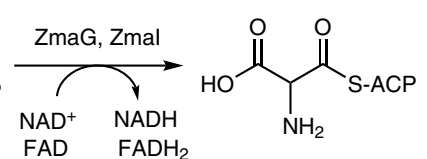<smiles>[R]C1=C(C)C(=O)c2ccccc2C1=O</smiles>
VKDC $\downarrow \mathrm{O}_{2} \quad$ Warfarin $-\uparrow$ VKOR

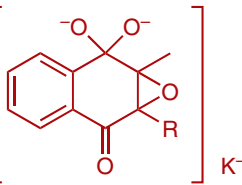<smiles>[2H]C1(C)C(=O)c2ccccc2C(=O)C1(C)C</smiles><smiles>CC(C)=CCC=C(C)CCC=C(C)C</smiles>
Menaquinones (vitamin K2)

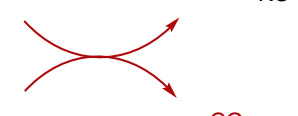

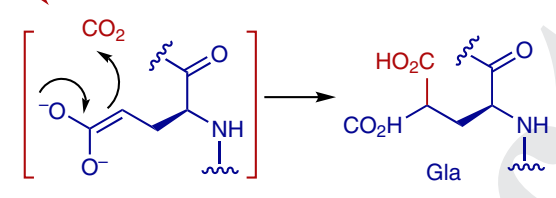

VKD proteins

Gla<smiles>C/C(=C\C[14CH3])CCCC(C)C</smiles>

Phylloquinone (vitamin K1)

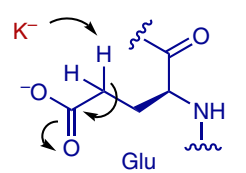

Fig. 1 | Biosynthesis of malonic acid derivatives. a, Malonomycin 1 contains an intact aminomalonate moiety. $\mathbf{b}$, Biosynthesis of malonates in primary and secondary metabolism ( $\mathrm{R}=\mathrm{H}$ or alkyl). c, Proposed mechanism of the mammalian VKDC. Phylloquinones (vitamin K1) are utilized in mammalian VKDC as cofactors, while menaquinones (vitamin K2) with variable isoprenoid side-chain lengths are produced by bacteria, including Streptomyces, and may serve a similar role in bacterial VKDC-like enzymes. ACC, acetyl-CoA carboxylase; ACP, acyl carrier protein; CCR, crotonyl-CoA carboxylase/reductase enzymes; Gla, $\boldsymbol{\gamma}$-carboxyglutamic acid; $\mathrm{K}$, vitamin $\mathrm{K}$ quinone form; $\mathrm{K}^{-}$, vitamin $\mathrm{K}$ oxygenated intermediate; VKOR, KO reductase.

VKDC. Key catalytic residues within the human VKDC, including $\mathrm{K} 218$ and $\mathrm{H} 160$, which are proposed to be involved in vitamin $\mathrm{K}$ co-factor deprotonation and substrate glutamyl carboxylation, respectively ${ }^{16,17}$, are also conserved in $\mathrm{MloH}$ (Supplementary Fig. 1). Whereas the human VKDC utilises vitamin $\mathrm{K}$ phylloquinone (vitamin K1), bacteria including Streptomyces possess vitamin K menaquinones (vitamin K2), which are mainly used in respiration and ATP generation (Fig. 1c) ${ }^{18-20}$. Similar to the human enzyme, $\mathrm{MloH}$ is predicted to possess multiple transmembrane domains centred within a conserved horizontally transferred transmembrane (HTTM) domain characteristic of VKDC (Supplementary Fig. 1). This HTTM domain is horizontally transferred from metazoan VKDCs to bacteria and, to date, the only known function for proteins possessing this HTTM domain is as VKDC enzymes ${ }^{21}$.

This suggests that MloH is an integral membrane protein within the $S$. rimosus cell membrane, and thus carboxylation probably occurs as a final biosynthetic step before malonomycin is exported.

Characterization of the mlo BGC. Both S. rimosus strains were cultivated and analysed for production of malonomycin 1 . R2374 gave a much higher yield of $1\left(67 \mathrm{mgl}^{-1}\right)$ than NRRL $2455\left(2 \mathrm{mgl}^{-1}\right)$, as confirmed by reversed-phase high-performance liquid chromatography (RP-HPLC), liquid chromatography-high resolution mass spectrometry (LC-HRMS) and NMR (Supplementary Fig. 2 and Supplementary Table 3), and was chosen for further studies. To investigate the biosynthesis of $\mathbf{1}$, mloABDLMN genes were inactivated individually by clustered regularly interspaced short palindromic repeats (CRISPR)-CRISPR-associated protein 9 (Cas9) gene editing ${ }^{22}$. Although MloIJ appears to possess all of the domains required for premalonomycin $\mathbf{5}$ assembly, $m l o A B$ encodes two additional NRPS modules, the deletion of which significantly impaired production of 1 (Supplementary Fig. 3a). This, coupled with the presence of a condensation domain, rather than the usual adenylation domain, at the amino $(\mathrm{N})$ terminus of MloI, suggests that MloAB may be a functional component of the assembly line (Supplementary Fig. 3b,c), initiating peptide assembly and installing amino acids at the Ser residue of malonomycin precursors that are subsequently cleaved by a protease, as seen for some other NRPS products $^{23-25}$. To investigate this, the $\mathrm{N}$-terminal MloI condensation domain was deactivated using CRISPR-Cas9 to mutate the catalytic His residue (H146A), which is known to be essential for the activity of condensation domains ${ }^{26,27}$. The resultant strain produced only a trace amount of $\mathbf{1}$, similar to the $\triangle m l o A$ strain (Supplementary Fig. 4). An mloA S546A mutation was similarly introduced onto the chromosome, blocking phosphopantetheinylation of the MloA peptidyl carrier protein domain, which also resulted in only a trace amount of 1 . In addition, complementation of the $\triangle m l o A$ strain with the $m l o A(\mathrm{~S} 546 \mathrm{~A})$ mutant gene failed to restore malonomycin production, whereas complementation of $\triangle m l o A$ with $m l o A$ restored production to wild-type levels (Supplementary Fig. 4). Given that phosphopantetheinylation of MloA and a catalytically active MloI $\mathrm{C}_{1}$-domain are both required for efficient production of malonomycin, it is likely that MloA fulfils a catalytic function, transferring an aminoacyl or peptidyl precursor to MloI via its N-terminal condensation domain, generating a propeptide that is subsequently processed. The observations that the MloA and MloI $\mathrm{C}_{1}$ domain mutants can still produce trace quantities of 1 suggest that MloI can initiate peptide assembly with L-Ser, albeit very inefficiently.

As malonomycin is exported out of the cell in the wild-type strain, the putative $\mathrm{ABC}$ transporter $m l o D$ was targeted for inactivation. In the absence of the transporter, it was envisaged that precursors, including propeptides, might accumulate within the cell, allowing their detection. While the resultant $\Delta m l o D$ strain showed no evidence of malonomycin or premalonomycin in the fermentation media, LC-HRMS analysis of cellular extracts from $\Delta m l o D$, and also wild-type strains, has so far failed to identify the presence of malonomycin propeptides. However, the possibility that propeptide precursors exist cannot be ruled out.

Of the remaining genes in the mlo cluster, inactivation of either $m l o L$ or $m l o N$ had no effect on malonomycin production; however, deletion of mloM-a putative LuxR-type transcriptional regulator-abolished production of $\mathbf{1}$. Complementation of $\Delta m l o M$ with constitutively expressed mloM resulted in 5.5-fold enhanced production of 1 ( $\left.370 \mathrm{mgl}^{-1}\right)$ over the wild-type R2374. Expression of the R2374 mloM in NRRL 2445 also increased titres of 1 140-fold $\left(267 \mathrm{mgl}^{-1}\right.$ ) over the parent strain (Table 1$)$, confirming MloM is a positive regulator of the mlo BGC.

MloI activates L-Asp via the side-chain carboxyl group. To further elucidate the biosynthesis of malonomycin $\mathbf{1}$, we explored the 

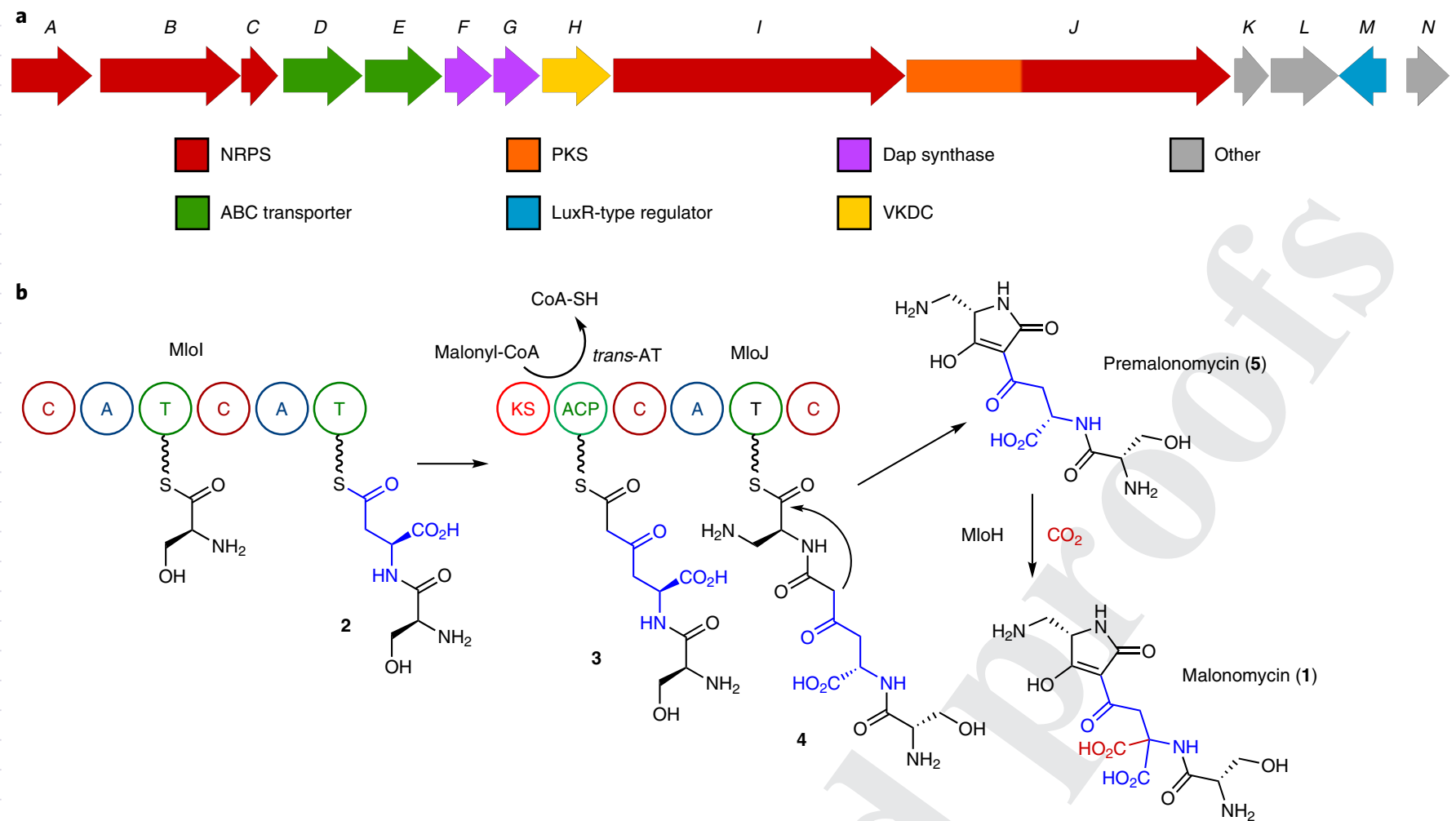

Fig. 2 | Malonomycin ( $m / 0)$ gene cluster and biosynthetic pathway. a, Organization of genes in the malonomycin (mlo) cluster. b, Proposed pathway for malonomycin 1 biosynthesis. The dipeptide $\mathbf{2}$ from Mlol is condensed with a malonate unit introduced by a trans-AT enzyme encoded by either mloK, or a gene elsewhere in the genome, to generate $\mathbf{3}$. Condensation with L-Dap gives $\mathbf{4}$ and subsequent Dieckmann cyclisation catalysed by MloJ $C_{2}$ yields premalonomycin 5. Finally, premalonomycin is carboxylated by MloH, a VKDC-like enzyme that likely resides in the cell membrane due to its predicted multiple transmembrane domains, to give malonomycin 1 . A, adenylation domain; ACP, acyl carrier protein; AT, acyltransferase domain; $C$, condensation domain; Dap, L-2,3-diaminopropionic acid; KS, ketosynthase domain; T, thioesterase domain.

specificity and regioselectivity of the MloI $\mathrm{A}_{2}$ domain, to establish whether L-Asp activation occurs via the side-chain carboxyl (Fig. 3a). MloI $\mathrm{A}_{2} \mathrm{~T}_{2}$ didomain was overproduced in Escherichia coli and assayed for adenylation activity ${ }^{28}$. Activity was observed with L-Asp and at a lower level with L-Asn, while the 18 other amino acids including D-Asp showed little or no activity (Fig. 3b).

Table 1 | Titres of compounds from S. rimosus strains generated in this study

Strain

Calculated compound titres $\left(\mathrm{mgl}^{-1}\right)$

Production of 1 as $\%$ of wild type

1212

$\Delta m l o H$

$\Delta m l o H:: m l o H$

$\Delta m l o H:: N g$ orf44

$\Delta \mathrm{mloH}:: \mathrm{mloH}$ (K182A)

$\Delta m l o H:: m l o H(K 182 \mathrm{H})$

$\triangle \mathrm{mloH}:: \mathrm{mloH}(\mathrm{K} 182 \mathrm{R})$

$\triangle m l o H:: m l o H(H 119 K)$

$\Delta m l o H:: m l o H(H 119 R)$

$\Delta m l o M$

$\triangle m l o M:: m l o M$

Wild-type NRRL 2455

NRRL 2455::mloM
Wild-type R2374

$\triangle m l o H:: m l o H(H 119 A)$

$67.2 \pm 4.2$

0

$59.8 \pm 10.9$

$35.9 \pm 9.6$

$3.1 \pm 0.5$

$1.3 \pm 0.6$

0

0

0

$0.2 \pm 0.1$

0

$369.3 \pm 88.1$

$1.9 \pm 0.3$

$266.7 \pm 10.7$

\section{$3.1 \pm 2.0$}

$6.9 \pm 2.7$

$3.6 \pm 0.7$

$5.8 \pm 2.4$

$3.0 \pm 0.7$

$5.0 \pm 2.9$

$3.6 \pm 1.5$

$2.6 \pm 0.1$

$4.5 \pm 2.2$

$3.2 \pm 0.9$

0

0

0

0

\section{2}

$\begin{array}{ll}1.0 \pm 0.4 & 100.0 \\ 8.7 \pm 3.7 & 0 \\ 1.2 \pm 0.2 & 89.0 \\ 3.9 \pm 1.5 & 53.4 \\ 4.4 \pm 0.9 & 4.5 \\ 6.1 \pm 2.9 & 1.9 \\ 3.9 \pm 1.9 & 0 \\ 3.3 \pm 0.4 & 0 \\ 6.1 \pm 2.6 & 0 \\ 3.4 \pm 0.6 & 0.4 \\ 0 & 0 \\ 0 & 549.2 \\ 0 & 100.0 \\ 0 & 13818.7\end{array}$

Quantification of malonomycin 1, premalonomycin $\mathbf{5}$ and $\mathrm{N}$-succinylated-premalonomycin $\mathbf{1 2}$ was based on $50 \mathrm{ml}$ cultures in at least triplicate. Culture supernatants were partially purified to generate crude extracts that were analysed by RP-HPLC. Peak areas were calculated and compared with a standard curve to calculate titres. Values represent means, and errors denote s.d. values, with $n \geq 3$. 
<smiles>COC(=O)C[C@H](N)C(=O)O</smiles><smiles>COC(=O)C(N)CC(=O)O</smiles><smiles>N[C@@H](CC(=O)O)C(=O)O</smiles>

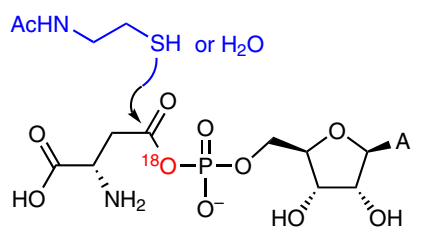

10<smiles>CNCCSC(=O)C[C@H](N)C(=O)O</smiles>

b
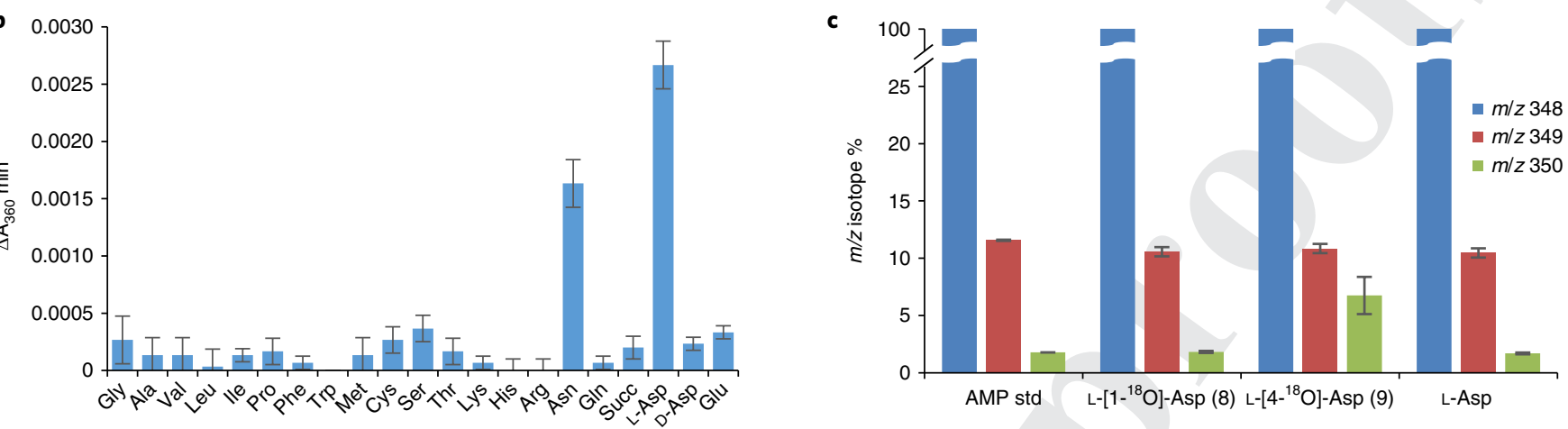

d
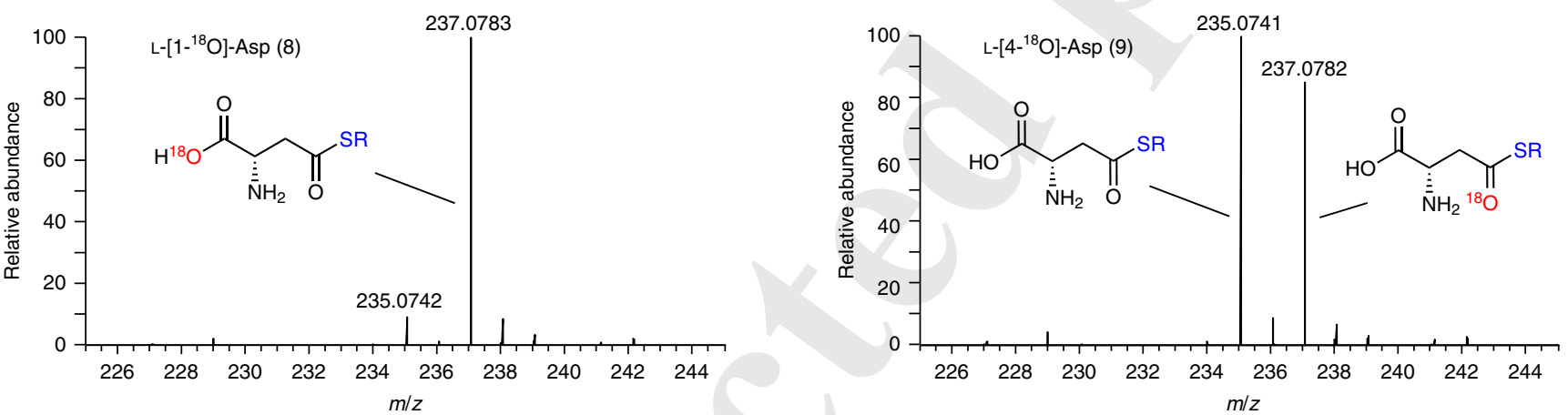

Fig. 3 | Substrate selectivity of Mlol $\mathbf{A}_{2} \mathbf{T}_{2}$ didomain and L-Asp substrate side-chain activation. $\mathbf{a}$, Reaction scheme for monitoring the substrate selectivity and regiospecificity of Mlol. Hydrolysis of L-Asp O-methyl esters $\mathbf{6}$ and $\mathbf{7}$ with $\mathrm{Na}^{18} \mathrm{OH}$ generates ${ }^{18} \mathrm{O}$-labelled L-Asp isotopomers 8 and $\mathbf{9}$ with around $90 \%$ ${ }^{18} \mathrm{O}$ enrichment. Cognate substrates forming an aminoacyl-adenylate intermediate 10 lead to PPi release, which is monitored in real time using a 7-methyl6-thio-guanosine-based spectrophotometric assay ${ }^{28}$. Transfer of an ${ }^{18} \mathrm{O}$ label onto AMP 11 or retention of the ${ }^{18} \mathrm{O}$ label in the Asp-SNAC thioester 12 is dependent on the isotopomer used and the regioselectivity of the Mlol $A_{2} T_{2}$ enzyme. $\mathbf{b}$, Adenylation domain activity assays of Mlol $A_{2} T_{2}$ show significant activation of L-Asp. Values represent means, and error bars denote s.d., with $n=3$. c, LC-HRMS analysis of AMP generated from assays of Mlol with ${ }^{18} \mathrm{O}$ LAsp isotopomers reveals transfer of the ${ }^{18} \mathrm{O}$ label to AMP with L-[4- $\left.{ }^{18} \mathrm{O}\right]$-Asp 9 (increased $\mathrm{m} / \mathrm{z} 350$ ), but not with L-[1-18 O]-Asp 8. Values represent means,

211 and error bars denote s.d., with $n=3$. d, LC-HRMS of Asp-SNAC thioesters generated from L-[1-18 O]-Asp 8 and L-[4-18 O]-Asp 9. Taking into account that both isotopomers 8 and $\mathbf{9}$ were around $90 \%{ }^{18} \mathrm{O}$ enriched at the outset, the SNAC thioester derived from 8 retained $>99 \%$ of the ${ }^{18} \mathrm{O}$ label, whereas thiolation of 9 resulted in around $50 \%$ loss of ${ }^{18} \mathrm{O}$. Given that only one of the two oxygen atoms of the carboxyl group is labelled and only half of the ${ }^{18} \mathrm{O}$ can be lost on thiolation, these assays show that Mlol $\mathrm{A}_{2}$ is highly selective (around 99\% selective) for the C4 carboxyl group. LC-HRMS data: Asp-SNAC $[\mathrm{M}+\mathrm{H}]+\mathrm{m} / \mathrm{z}$ : calculated 235.0747, observed 235.0742. ${ }^{18} \mathrm{O}-\mathrm{Asp}-\mathrm{SNAC}[\mathrm{M}+\mathrm{H}]+\mathrm{m} / \mathrm{z}$ : calculated 237.0789, observed 237.0783.

${ }^{18} \mathrm{O}$-labelled L- $\left[1-{ }^{18} \mathrm{O}\right]$-Asp 8 and L- $\left[4-{ }^{18} \mathrm{O}\right]$-Asp 9 were then synthesized and incubated with MloI $\mathrm{A}_{2} \mathrm{~T}_{2}$ and ATP. Transfer of the ${ }^{18} \mathrm{O}$

Q9 label from the C4 (side-chain) carboxyl of 9 to adenosine mono-

Q10 phosphate (AMP) was observed, but not from the $\mathrm{C} 1$ carboxyl of 8 (Fig. 3c). Although MloI $\mathrm{A}_{2} \mathrm{~T}_{2}$ shows clear regioselectivity for the $\mathrm{C} 4$ carboxyl of $\mathrm{L}$-Asp, the incorporation of ${ }^{18} \mathrm{O}$ into AMP was low. This may be due to background ATPase activity of the adenylation domain ${ }^{29}$ when removed from its native assembly line. For additional confirmation of the MloI $\mathrm{A}_{2}$ regioselectivity, a second thiolation assay was developed using $N$-acetylcysteamine (SNAC) to capture Asp from the Asp-AMP intermediate 10 (Fig. 3a,d). Analysis of the Asp-SNAC thioesters produced from incubating MloI $\mathrm{A}_{2} \mathrm{~T}_{2}$ with ATP, SNAC and isotopomers 8 or $\mathbf{9}$ confirmed that the $\mathrm{A}_{2}$ domain is highly selective for the L-Asp side-chain carboxyl group, consistent with the proposed pathway (Fig. 2b). Control experiments carried out with a standard L-Asp-activating adenylation domain $\left(\mathrm{A}_{2}\right)$ from the surfactin NRPS (SrfAB) ${ }^{30}$ showed the reverse isotopic labelling patterns of what was expected (Supplementary Fig. 5).

Characterization of the bacterial VKDC orthologue MloH. Next, we deleted the putative VKDC-like enzyme MloH (Supplementary Fig. 6a,b). Production of malonomycin 1 was abolished in the $\Delta m l o H$ strain, and two new compounds 5 and $\mathbf{1 2}$ were produced at significant titres (Fig. $4 \mathrm{a}$ and Table 1). Compound $\mathbf{5}$ was shown to be identical, as judged by RP-HPLC, LC-HRMS and mass spectrometry ${ }^{2}$ (Supplementary Fig. 6c,d and Supplementary 

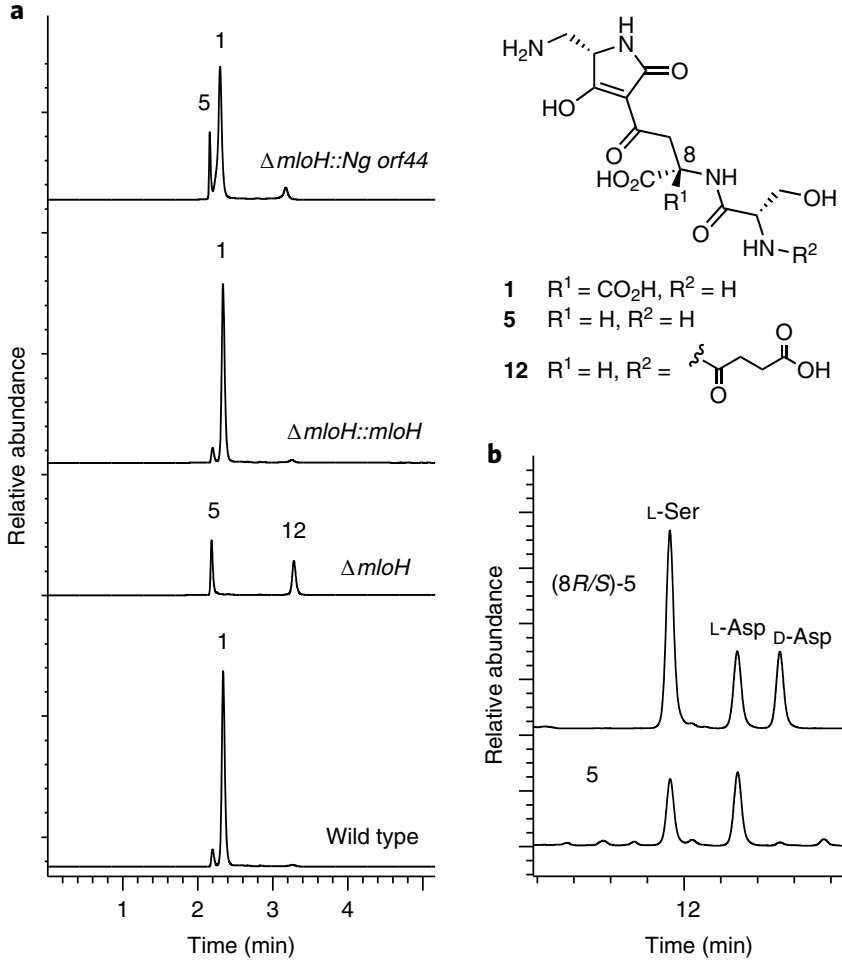

Fig. 4 | Characterization of compounds from wild-type and engineered strains. a, RP-HPLC analysis of extracts from R2374 wild type, $\Delta m l o H, \Delta$ $\mathrm{mloH}:: \mathrm{mloH}$ and $\Delta \mathrm{mloH}:: \mathrm{Ng}$ orf 44 strains. Production of malonomycin $\mathbf{1}$ is observed in the wild-type strain, but is abolished in the VKDC deletion strain $\Delta m l o H$, which produces compounds premalonomycin $\mathbf{5}$ and $\mathrm{N}$ succinylated premalonomycin 12. Complementation of $\Delta \mathrm{mloH}$ with either the wild-type $\mathrm{mloH}$ or orf44 from N. gamkensis restores production of 1. b,

Q12 RP-HPLC analysis of acid hydrolysates of decarboxylated malonomycin (8R/S)-5 and premalonomycin 5, following derivatization with Marfey's reagent. Premalonomycin $\mathbf{5}$ hydrolysis gives L-Ser and L-Asp only, indicating the (8S) configuration of $\mathbf{5}$.

Table 3), to thermally decarboxylated malonomycin (8R/S)-5. Complementation of the $\Delta m l o H$ strain with $m l o H$ restored production of 1 to wild-type levels. Thus, $\mathrm{MloH}$ is essential for the carboxylation of the precursor premalonomycin $\mathbf{5}$, to generate malonomycin 1. NMR experiments confirmed that $\mathbf{5}$ isolated from $\Delta m l o H$ is a single diastereoisomer, whereas the decarboxylated malonomycin $(8 R / S)-\mathbf{5}$ is a $1: 1$ mixture of diastereoisomers (Supplementary Figs. 7-9). Derivatization of the amino acids, derived from hydrolysis of $\mathbf{5}$, using Marfey's reagent ${ }^{31}$, revealed that 5 from $\Delta m l o H$ possesses both L-Ser and L-Asp, confirming the $(8 S)$ configuration of 5 (Fig. $4 \mathrm{~b}$ and Supplementary Fig. 6e), consistent with the activation of $\mathrm{L}$-Asp by MloI $\mathrm{A}_{2} \mathrm{~T}_{2}$ (Fig. 3b). The other metabolite $\mathbf{1 2}$ was shown by LC-HRMS, mass spectrometry ${ }^{2}$ and NMR analysis to be an $N$-succinylated premalonomycin derivative (Fig. 4 and Supplementary Figs. 10-14). Succinylation of peptide natural products has been reported, and may modify the biological activity as part of a host self-defence mechanism ${ }^{32-35}$. However, as no detectable quantity of succinylated $\mathbf{1}$, and only trace quantities $\left(1 \mathrm{mgl}^{-1}\right)$ of $\mathbf{1 2}$ are evident in the wild-type strain, we suggest that premalonomycin $\mathbf{5}$ accumulates in $\Delta m l o H$, and is adventitiously succinylated by the abundant cellular pool of succinyl-CoA to give the side product 12 .

Further evidence that $\mathrm{MloH}$ shares a similar catalytic function to the mammalian VKDC was obtained by site-directed mutagenesis. In the human enzyme, K218 and H160 are important for activity ${ }^{16,17}$.
A K218A mutation results in the loss of co-factor oxidation and $\gamma$-Glu carboxylation, suggesting that $\mathrm{K} 218$ deprotonates the $\mathrm{KH}_{2}$ co-factor ${ }^{16}$ (Fig. 1c). Conversely, a H160A mutant showed minimal carboxylation activity, but oxidation of $\mathrm{KH}_{2}$ to $\mathrm{KO}$ was unaffected, suggesting that $\mathrm{H} 160$ may help stabilize the reactive $\gamma$-glutamyl enolate intermediate during carboxylation ${ }^{17}$. Mutagenesis of the corresponding residues in $m l o H$ generated $\mathrm{K} 182 \mathrm{~A} / \mathrm{H} / \mathrm{R}$ or H119A/ $\mathrm{K} / \mathrm{R}$ mutants that were used to complement the $\Delta m l o H$ strain. Whereas the $\Delta m l o H:: m l o H$ strain produces 1 at wild-type levels, $\Delta m l o H:: m l o H(H 119 A)$ failed to restore the production of $\mathbf{1}$, suggesting that this residue is involved in carboxylation activity (Table 1). The K182A mutant reduced the production of 1 to less than $5 \%$ of the wild type. The human K218A mutant abolished enzyme activity, but could be rescued with the addition of exogenous amines, which are suggested to deprotonate the $\mathrm{KH}_{2}$ co-factor in the absence of the general base $\mathrm{K} 218$ (ref. ${ }^{16}$ ). It is therefore possible that the residual activity of MloH K182A could be a consequence of an alternative cellular amine or water functioning as a base. Substitutions by larger amino acids further reduced $(\mathrm{K} 182 \mathrm{H})$ or abolished $(\mathrm{K} 182 \mathrm{R})$ production (Table 1). Presumably, in K182R, the side chain is unable to adopt the geometry required to deprotonate $\mathrm{KH}_{2}$ and also blocks another molecule from functioning as a base. The MloH H116 residue, given its close proximity to $\mathrm{H} 119$, was also subjected to mutagenesis. In this case, $\mathrm{H} 116 \mathrm{~A} / \mathrm{K} / \mathrm{R}$ mutations all resulted in significant malonomycin production (Supplementary Fig. 15). These results suggest that the conserved K182 and $\mathrm{H} 119$ residues of $\mathrm{MloH}$ provide the same catalytic functions as the corresponding residues in the related human VKDC.

From BLAST analysis, it is apparent that there are a number of other VKDC-like proteins in bacteria exhibiting high similarity to $\mathrm{MloH}$. One such protein is encoded by orf44 from Nocardia gamkensis NBRC 108242 (52\% identity and 64\% similarity). The $N$. gamkensis orf44 is present in a BGC that resembles the mlo BGC (Supplementary Figs. 3d and 16). Unlike the NRRL 2455 and R2374 mlo BGCs, which share $>93 \%$ identity, the proteins in the Nocardia BGC exhibit between 40 and $60 \%$ identity to the corresponding mlo-encoded proteins. Efforts to isolate malonomycin-like metabolites from N. gamkensis, and from expression of the Nocardia BGC in the heterologous hosts Streptomyces coelicolor and Staphylococcus albus, have so far been unsuccessful. However, ORF44 exhibits $52 \%$ identity to $\mathrm{MloH}$, so we examined this protein for VKDC-like activity using orf44 to complement $\Delta m l o H$. The resulting strain $\Delta$ $m l o H:: N g$ orf 44 produced good quantities of 1 (53\% of that of the wild-type R2374 (Fig. 4a and Table 1)), confirming that two VKDClike enzymes from distinct bacterial genera have the ability to $\alpha$-carboxylate aspartyl precursors to generate intact aminomalonic acid structures in secondary metabolism.

\section{Conclusion}

In summary, a genomics-driven approach has been used to identify the BGC for malonomycin, revealing a bacterial VKDC orthologue $(\mathrm{MloH})$. Through gene knockout and complementation experiments, we showed that MloH is responsible for the $\alpha$ -carboxylation of an aspartyl precursor, generating the intact aminomalonic acid moiety of malonomycin. Site-directed mutagenesis of conserved active-site residues in $\mathrm{MloH}$ abolished activity, in line with previously reported effects in the human enzyme, as expected if $\mathrm{MloH}$ is a functional orthologue of VKDC. A second bacterial VKDC-like protein from Nocardia was also shown to share functionality with $\mathrm{MloH}$. Additionally, ${ }^{18} \mathrm{O}$-labelling experiments showed that $\mathrm{L}$-Asp is activated via its side-chain carboxyl group in an NRPS-PKS assembly line to deliver the premalonomycin precursor for subsequent carboxylation. This work provides functional characterization of VKDC-like enzymes of bacterial origin and reveals a highly unusual pathway to aminomalonic acid-containing metabolites. 


\section{Methods}

Materials. Chemical reagents and solvents were purchased from commercial sources (Sigma-Aldrich and Fisher Scientific) and used without further purification unless otherwise stated. Molecular biology enzymes were purchased from New England Biolabs unless otherwise stated. Oligos were synthesized by Sigma-Aldrich.

Nucleotide sequencing and assembly of the S. rimosus R2374 and NRRL 2455 genomes. Sequencing was carried out on an Illumina MiSeq platform using the Illumina V2 500 cycle kit run in $2 \times 250$ base pair (bp) mode, using around oneeighth of the full-run capacity for each library type. Nextera Shotgun and Nextera Matepair libraries were constructed from high-molecular-weight genomic DNA following the manufacturer's protocols. Reads were processed using an in-house Illumina adapter trimming tool (fastq_miseq_trimmer). Read pairs were then preassembled using FLASH version 1.2.11 (https://ccb.jhu.edu/software/FLASH/). The Nextera Matepair linker sequence was used for splitting of matepair reads (fastq_miseq_trimmer). Processed reads were assembled de novo using Newbler version 3 (Roche). Several assemblies were carried out using either all or subsets of the input dataset, and the best assembly was selected using a score calculated from the scaffold N50, edge count and total number of contigs.

Q14 Genome annotation. Coding sequences were predicted ab initio using fgeneSB version 2 (http://www.softberry.com/). Annotation was transferred by a set of in-house PERL scripts from the most representative hits to KEGG and Non-

15 Redundant databases. Coding sequences were colour coded according to the hits

Q16 to the Clusters of Orthologous Groups functional database. National Center for Biotechnology Information BLAST version 2.2.17 (ref. ${ }^{36}$ ) was used for protein database searches. The final annotation results were manually curated using Artemis (version 16) ${ }^{37}$

Production of malonomycin and derivatives. Procedures for the production of malonomycin and malonomycin derivatives were adapted from Schipper et al. as follows. A seed culture consisting of $20 \mathrm{ml}$ Tryptone Soy Broth (TSB) media in an Erlenmeyer flask containing a spring was inoculated with $50 \mu$ l of a stock suspension of $S$. rimosus subspecies paramyceticus R2374 spores. The seed culture was cultivated at $28^{\circ} \mathrm{C}$ with 150 r.p.m. agitation for $48 \mathrm{~h}$ and subsequently used to inoculate $70 \mathrm{ml}$ malonomycin production medium (malt extract (Oxoid) $18 \mathrm{gl}^{-1}$, peptone (Formedium) $7 \mathrm{gl}^{-1}$ and $\mathrm{NaCl} 5 \mathrm{gl}^{-1} ; \mathrm{pH} 8.5$ ) at $1 \% v / v$ in $250 \mathrm{ml}$ flasks containing springs. The fermentation cultures were cultivated for $65 \mathrm{~h}$ at $28^{\circ} \mathrm{C}$ with 150 r.p.m. agitation.

Isolation of malonomycin and derivatives. Fermentation cultures were centrifuged at $5,000 \mathrm{~g}$ to pellet the cells. The fermentation supernatant was reduced in volume tenfold under reduced pressure, adjusted to $\mathrm{pH} 2$ with $\mathrm{HCl}$ and centrifuged $(5,000 \mathrm{~g}$ for $10 \mathrm{~min})$ to pellet the precipitated media components and organic matter.

Procedures for the isolation of malonomycin and malonomycin derivatives were adapted from Schipper et al. ${ }^{3}$ as follows. For the isolation of malonomycin 1 from the wild-type R2374, the supernatant was adjusted to the isoelectric point of malonomycin ( $\mathrm{pH}$ 2.7) and 4 volumes of methanol were added, before incubating at $-20^{\circ} \mathrm{C}$ for $2 \mathrm{~h}$. The precipitated malonomycin was pelleted by centrifugation $\left(5,000 \mathrm{~g}\right.$ for $10 \mathrm{~min}$ at $\left.4^{\circ} \mathrm{C}\right)$, redissolved in $\mathrm{H}_{2} \mathrm{O}$ and adjusted to $\mathrm{pH}$ 8.5. The resultant crude extract was loaded over an anion exchange column consisting of DEAE-Sephadex A25 resin pre-swollen in $0.5 \mathrm{M}$ ammonium acetate ( $\mathrm{pH} 8.5$ ). Malonomycin 1 was eluted with a gradient of $0-1 \mathrm{M}$ acetic acid in stepwise $0.1 \mathrm{M}$ increments of 1.5 column volumes each. Fractions were collected and analysed by RP-HPLC (Phenomenex Kinetex XB-C18 column; $4.6 \mathrm{~mm} \times 250 \mathrm{~mm}$; $5 \mu \mathrm{m}$ particle size) using the following method: $240,280 \mathrm{~nm}$ ultraviolet absorbance, a $1 \mathrm{ml} \mathrm{min}^{-1}$ flow rate and a gradient of $0-4 \mathrm{~min} 3 \% \mathrm{~B}, 4-8 \mathrm{~min} 3-80 \% \mathrm{~B}, 8.1-10 \mathrm{~min}$ $95 \% \mathrm{~B}, 10-11 \mathrm{~min} 95-3 \% \mathrm{~B}$ and $11-14 \mathrm{~min} 3 \% \mathrm{~B}$, with mobile phase A consisting of $\mathrm{H}_{2} \mathrm{O}+0.1 \%$ formic acid and mobile phase $\mathrm{B}$ consisting of methanol $+0.1 \%$ formic acid. Fractions containing $\mathbf{1}$ were pooled and dried under reduced pressure. The resultant pale yellow-brown residue was washed with ice-cold $\mathrm{pH} 7.0 \mathrm{H}_{2} \mathrm{O}$, and 1 precipitated as a white crystalline solid. The liquid was removed after centrifugation and the wet pellet was frozen and lyophilised, yielding 1 (76 mg isolated from 11 culture).

Isolation of premalonomycin $\mathbf{5}$ from the $\Delta m l o H$ strain was carried out as described above, except anion exchange fractions containing premalonomycin $\mathbf{5}$ were pooled and dried under reduced pressure, redissolved in $\mathrm{H}_{2} \mathrm{O}$ and passed through a C18 Bondelut (Agilent). The flowthrough and water wash were pooled and lyophilised, yielding a light yellow-brown solid of 5 (46 mg isolated from 11 culture).

Compound 12 was purified from the $\Delta m l o H$ strain by semi-preparative RP-HPLC from the crude extract obtained after precipitation with methanol. A Varian ProStar HPLC with a Phenomenex Gemini C18 column $(10 \mathrm{~mm} \times 250 \mathrm{~mm}$; $5 \mu \mathrm{m}$ particle size) was used, with the following method: $240,280 \mathrm{~nm}$ ultraviolet absorbance and a gradient of $0-5 \min 3 \%$ B, $5-8 \min 3-70 \%$ B, $8-8.5$ min $70-95 \%$ B, $8.5-10 \min 95 \% \mathrm{~B}, 10-10.5 \mathrm{~min} 95-3 \% \mathrm{~B}$ and $10.5-12 \mathrm{~min} 3 \% \mathrm{~B}$, with mobile phase A consisting of $\mathrm{H}_{2} \mathrm{O}+0.1 \%$ formic acid and mobile phase $\mathrm{B}$ consisting of methanol $+0.1 \%$ formic acid. Fractions containing compound 12 were pooled and dried under reduced pressure, redissolved in water and loaded over a cation exchange column consisting of Dowex 50WX8 resin pre-swollen in $\mathrm{H}_{2} \mathrm{O}$. The column was washed with $\mathrm{H}_{2} \mathrm{O}$ and 12 was eluted with $1 \mathrm{M} \mathrm{NH} \mathrm{N}_{4} \mathrm{OH}$.

Characterization of malonomycin and derivatives. LC-HRMS characterization of all malonomycin-related compounds was carried out using a Thermo Dionex UltiMate 3000 UHPLC coupled to a Thermo Q Exactive spectrometer with the following method: (Thermo Accucore C18 column, $2.1 \mathrm{~mm} \times 100 \mathrm{~mm} ; 2.6 \mu \mathrm{m}$ particle size), a $0.3 \mathrm{ml} \mathrm{min}^{-1}$ flow rate and a gradient of $0-3 \mathrm{~min} 3 \% \mathrm{~B}, 3-6.5 \mathrm{~min}$ $3-95 \%$ B , 6.5-8.5 min 95\% B, 8.5-9 min 95-3\% B and 9-12 min 3\% B, with mobile phase A consisting of $\mathrm{H}_{2} \mathrm{O}+0.1 \%$ formic acid and mobile phase $\mathrm{B}$ consisting of methanol $+0.1 \%$ formic acid. Multiple-stage mass spectrometry analysis of malonomycin and related compounds was carried out on a Waters ACQUITY UPLC coupled to an LTQ Orbitrap XL with a Phenomenex Kinetex C18 column $(2.1 \mathrm{~mm} \times 100 \mathrm{~mm} ; 2.6 \mu \mathrm{m}$ particle size $)$ and a gradient as described previously. Fragmentation settings were set as targeted multiple-stage mass spectrometry (iso width $=0.5 \mathrm{~m} / z ; \mathrm{CID}=20 ; 30 \mathrm{eV})$. For NMR analysis, compounds were dissolved in $\mathrm{D}_{2} \mathrm{O} / \mathrm{DCl}(\mathbf{1}), \mathrm{D}_{2} \mathrm{O}(5$ and $(8 R / S)-5)$ or $\mathrm{D}_{2} \mathrm{O}: \mathrm{H}_{2} \mathrm{O}$ 1:9 (12) (for further details of NMR assignments; see the Supplementary Methods).

Stereochemistry of premalonomycin (5). A thermally decarboxylated malonomycin standard $(8 R / S)-\mathbf{5}$ was generated by suspending malonomycin $\mathbf{1}$ in $\mathrm{H}_{2} \mathrm{O}$ and heating at $100^{\circ} \mathrm{C}$ for $10 \mathrm{~min}$. Premalonomycin $\mathbf{5}$ and decarboxylated malonomycin $(8 R / S)-5$ were hydrolysed in $6 \mathrm{M} \mathrm{HCl}$ at $98^{\circ} \mathrm{C}$ for $3 \mathrm{~h}$ before derivatization with 1-fluoro-2-4-dinitrophenyl-5-L-alanine amide (Marfey's reagent $)^{31}$ using standard procedures. Standards of L-Asp, D-Asp, L-Ser and DSer were directly derivatized without previous $\mathrm{HCl}$ treatment. The samples were analysed on an Agilent Infinity 1200 series HPLC (Phenomenex Kinetex XB-C18 column; $4.6 \mathrm{~mm} \times 250 \mathrm{~mm} ; 5 \mu \mathrm{m}$ particle size) with the following method: $340 \mathrm{~nm}$ ultraviolet absorbance, a $1 \mathrm{ml} \mathrm{min}^{-1}$ flow rate and a gradient of $0-1 \mathrm{~min} 5 \% \mathrm{~B}$, $1-19 \min 5-70 \% \mathrm{~B}, 19-20 \min 95 \% \mathrm{~B}, 20-22 \mathrm{~min} 95 \% \mathrm{~B}, 22-23 \min 95-5 \% \mathrm{~B}$ and 23-25 min 5\% B, with mobile phase A consisting of $\mathrm{H}_{2} \mathrm{O}+0.05 \%$ trifluoroacetic acid and mobile phase $\mathrm{B}$ consisting of acetonitrile $+0.05 \%$ trifluoroacetic acid. They were also analysed by LC-HRMS on a Thermo Dionex UltiMate 3000 UHPLC coupled to a Thermo Q Exactive spectrometer with the following method: (Thermo Accucore C18 column; $2.1 \mathrm{~mm} \times 100 \mathrm{~mm} ; 2.6 \mu \mathrm{m}$ particle size), a $0.3 \mathrm{ml} \mathrm{min}^{-1}$ flow rate and a gradient of $0-2 \min 5 \% \mathrm{~B}, 2-10 \mathrm{~min} 5-70 \% \mathrm{~B}, 10-$ $10.5 \min 70-95 \%$ B, $10.5-12.5$ min $95 \%$ B, $12.5-13$ min $95-5 \%$ B and $13-15$ min $5 \%$ $\mathrm{B}$, with mobile phase A consisting of $\mathrm{H}_{2} \mathrm{O}+0.1 \%$ formic acid and mobile phase $\mathrm{B}$ consisting of methanol $+0.1 \%$ formic acid. In addition to RP-HPLC and LC-HRMS analysis, the derivatized hydrolysates of $\mathbf{5}$ and $(8 R / S)-\mathbf{5}$ were run with co-injections of derivatized L- and D-Asp and Ser standards to identify the component amino acids present in each sample.

Synthesis of $\mathrm{N}$-succinylated regioisomers and characterization of $\mathrm{N}$-succinylpremalonomycin (12). Premalonomycin $5(1 \mathrm{mg} ; 3 \mu \mathrm{mol})$ was treated with succinic anhydride $(2.5 \mathrm{mg} ; 25 \mu \mathrm{mol})$ in $10 \mathrm{mM}$ phosphate buffer $\mathrm{pH} 6.5$ at $21^{\circ} \mathrm{C}$ for $16 \mathrm{~h}$, generating two regioisomers of $\mathrm{N}$-succinylated premalonomycin, with succinylation occurring on either the tetramic acid aminomethyl side chain or the amine of the serinyl moiety. The reaction was analysed by RP-HPLC, with co-injection of $\mathbf{1 2}$ isolated from the $S$. rimosus $\Delta m l o H$ strain identifying the earlier-eluting regioisomer as the natural product 12. Characterization of the two regioisomers by mass spectrometry ${ }^{2}$ and two-dimensional NMR (COSY and NOESY) revealed the early-eluting peak 12 to be succinylated on the serinyl moiety and the later eluting peak to be succinylated on the tetramic acid moiety.

CRISPR-Cas9 inactivation of $m l o H$ and other open reading frames (ORFs). Inactivation of $m l o H$, encoding a putative bacterial VKDC orthologue, was carried out by in-frame deletion using CRISPR-Cas9 (ref. ${ }^{22}$ ). A 102-bp region, encoding putative active-site residues, was targeted for deletion to prevent polar effects on flanking ORFs. A single protospacer insert was generated using primers ZY56F (5'-ACGCATCAGGCGGGAGAGCCACGG-3') and ZY56R (5'- AAACCCGTGGCTCTCCCGCCTGAT-3), and subsequently inserted into pCRISPomyces-2 using Golden Gate assembly. A 996-bp thiostrepton resistance cassette $(t s r)$ amplified from pIJ6021 using primers ZY59F (5'-GGAGGGAAAGTG CAATGTACCTGATCAAGGCGAATACTTC-3') and ZY59R (5'-CTGGAGGGAA ACCAGCGTACTGATCATCACTGACGAATCG-3') was then inserted using the SnaBI site using HiFi assembly (New England Biolabs), as a selectable marker due to the inherent resistance of $S$. rimosus $\mathrm{R} 2374$ against apramycin (pCRISPomyces-2 selective marker). Finally, homologous regions flanking the 102-bp deletion site were amplified using primers ZY57F (5'-TGCCGCCGGGCG TTTTTTATGGCGGTGTTGACGGGCAGAT-3'), ZY57R (5'-CATGTTCGCCGG CGGAGTGGTGATGCTGGACAGCCCGGTC-3'), ZY58F (5'-GACCGGGCTGT CCAGCATCACCACTCCGCCGGCGAACATG-3') and ZY58R (5'-TTACGGTTC CTGGCCTCTAGGCGAGGACTCCGTGCTGGTC-3'), inserted at the XbaI site using HiFi assembly (generating the construct $\mathrm{pCm} 2$-tsr-mloH), and verified by restriction digestion and nucleotide sequencing. To generate the $\mathrm{mloH}$ deletion in S. rimosus, pCm2-tsr-mloH was used to transform 
E. coli ET12567 (pUZ8002) and subsequently introduced into S. rimosus

222 R2374 by conjugation. Exconjugants were picked to SFM agar plates containing thiostrepton $\left(30 \mu \mathrm{g} \mathrm{ml}^{-1}\right)$ and cultivated at $30^{\circ} \mathrm{C}$ for $2-3 \mathrm{~d}$. Deletion of $102 \mathrm{bp}$ from $m l o H$ was verified by colony PCR amplification of the internal region of $m l o H$ using primers ZY70F (5'-CCCAGTAGGCGGGCATCATC-3') and ZY70R (5 -ACGACTTCTCCCTCGACGGC-3). Colonies showing deletion of $102 \mathrm{bp}$ from mloH were further cultivated on SFM at high temperature $\left(37-39^{\circ} \mathrm{C}\right)$ to promote loss of the plasmid. Replica plating on SFM with and without thiostrepton was used to screen for $\mathrm{mloH}$ mutants without plasmid. Gene inactivation of other mlo ORFs was carried out similarly, using the primers and plasmids detailed in Supplementary Tables 4 and 5. For point mutations introduced to the chromosome using CRISPR-Cas9, the target codons were altered on the homologous flanking arms used for DNA repair after Cas9 cleavage. The plasmids were constructed as described previously.

Complementation of the $\Delta m l o H$ strain and other ORFs. A tsr amplified from pIJ6021 using primers ZY65F (5'-TGAAAAACGCTCACTGGTACCTGATCA AGGCGAATACTTC-3') and ZY65R (5'-CAAGCTTAGATCTATGCATGTGA TCATCACTGACGAATCG-3') was inserted into the $\Phi$ ВT1-integrative plasmid pAV11b (a gift from M. Smith at the University of York) at the KpnI site using $\mathrm{HiFi}$ assembly, regenerating the $K p n \mathrm{I}$ site. The constitutive promoter $\operatorname{ermE}^{\star} \mathrm{p}$ was amplified from pIJ86 using primers ZY72F (5'-TGAAGTATTCGCCTTGATCAG TACCAGCCCGACCCGAGCA-3') and ZY72R (5'-AGCCACCAGTGCGTGAT CATATGTCCGTACCTCCGTTGCT-3), and $m l o H$ ( 1.5 kilobases) was amplified from $S$. rimosus 2374 genomic DNA using primers ZY73F (5'-AGCAACGGAG GTACGGACATATGATCACGCACTGGTGGCT-3') and ZY73R (5'-GAAAAAC GCTCACTGGTACCTCACCGGACGGGCTCCCCGA-3'). Both fragments were inserted into the KpnI site of the pAV11b-tsr plasmid using HiFi assembly (New England Biolabs), generating construct pAV11b-tsr-mloH, carrying the wild-type $m l o H$ gene under control of the $\mathrm{ermE}^{*}$ constitutive promoter. The plasmid was subsequently introduced into the $S$. rimosus $\mathrm{R} 2374 \Delta m l o H$ strain by conjugation using E. coli ET12567 (pUZ8002). Thiostrepton-resistant exconjugants after overlay with thiostrepton $\left(30 \mu \mathrm{g} \mathrm{ml}^{-1}\right)$ and nalidixic acid $\left(25 \mu \mathrm{g} \mathrm{ml}^{-1}\right)$ were picked to fresh SFM agar plates supplemented with thiostrepton and subsequently used to inoculate Tryptone Soy Broth liquid cultures. Genomic DNA was extracted, and successfully complemented colonies were verified by PCR using primers ZY70F and R. Other complementation plasmids for mlo knockout strains were constructed similarly using the primers and plasmids detailed in Supplementary Tables 4 and 5 .

Site-directed mutagenesis of MloH and other Mlo proteins. To generate point mutations of putative catalytic residues of the $S$. rimosus R2374 VKDC, plasmid pAV11b-tsr-mloH used to complement the $\Delta m l o H$ strain was subjected to sitedirected mutagenesis using a Q5 site-directed mutagenesis kit (New England Biolabs) with primers K182X F (5'-GGAGTGGCCNNNGTCCGCTAC GGCTGG-3'), where NNN is GCC (K182A), CAC (K182H) or CGC (K182R), and K182X R (5'-GCCGGCGAACATGGTGTACGCGAGG-3); H116X F (5'-GGGGCCAANNNGTCCACGCACTC-3), where NNN is GCC (H116A), CAC (H116K) or CGC (H116R), and R1 (H116A/K)

(5'-CAGCGCACCGGCGTTGACCGC-3) or R2 (H116R)

(5'-CAGCGCACCGGCGTTGACC-3'); and H119X F (5'-CACTCC ACGNNNTCGGCGCTCTACGC-3'), where NNN is GCC (H116A), CAC (H116K) or CGC (H116R), and R (5'-GTTGGCCCCCAGCGCACCGG-3), to introduce a single codon change at positions K182, H116 or H119, respectively. Mutations were verified by nucleotide sequencing (GATC Biotech) and the plasmids were conjugated into $S$. rimosus $\mathrm{R} 2374 \Delta m l o H$ using standard procedures. Single-colony exconjugants were picked and selected for on thiostreptoncontaining SFM agar plates, and integration of the mutant plasmids was verified by PCR. Construction of the $m l o A(S 546 \mathrm{~A})$ complementation plasmid was carried out similarly, except primers S546A F (5'-GGTCACGCGCTGCTGGCGTTCCGC-3) and S546 R (5'-GCCCAGGCCGAAGAAGTCCTCGTC-3) were used to generate the point mutation, with pAVIIb-tsr-mloA as a template. Additional non-catalytic point mutations to $\mathrm{mloH}$ to confirm that mutations did not affect $\mathrm{MloH}$ protein structure and activity were made using pAVIIb-tsr-mloH as a template and the primers listed in Supplementary Tables 4 and 5.

Cloning and purification of recombinant MloA, MloI $\mathrm{A}_{2} \mathrm{~T}_{2}$ and $\operatorname{SrfAB} \mathrm{A}_{2}$ proteins. The $m l o A$ gene was PCR amplified from S. rimosus $\mathrm{R} 2374$ genomic DNA using primers mloA-AT F (5'-AAAAAACATATGACAA GCACCCCAGGCGTCGG-3') and mloA-AT R (5'-AAAAAACTCGAGAC GCGCGGCGTCGACAGCC-3). The PCR product was doubly digested with NdeI and $X h o I$ restriction enzymes and ligated into a similarly digested pET21b vector. The resultant construct pET21b-mloA was used to transform E. coli BL21 for protein production.

The gene encoding the MloI $\mathrm{A}_{2} \mathrm{~T}_{2}$ didomain was PCR amplified from S. rimosus $\mathrm{R} 2374$ genomic DNA using the primers mloI- $\mathrm{A}_{2} \mathrm{~T}_{2} \mathrm{~F}\left(5^{\prime}\right.$-AAAAAAC ATATGTACTCGCTGGTCCTGCCCTCGCC-3) and $m l o I-\mathrm{A}_{2} \mathrm{~T}_{2} \mathrm{R}$ (5'-AAAA AACTCGAGGAAGTCATGCTCGGAAACCTCGTCTTCC-3'). The resultant DNA product was doubly digested with $\mathrm{NdeI}$ and $\mathrm{XhoI}$ and ligated into a similarly digested pET21b vector, generating construct pET21b-mloI- $\mathrm{A}_{2} \mathrm{~T}_{2}$. The resultant plasmid was used to transform $E$. coli BL21 for protein production.

The gene encoding the SrfAB $\mathrm{A}_{2}$ domain $^{30}$ was PCR amplified from genomic DNA extracted from Bacillus subtilis strain 168 using primers SrfAB- $\mathrm{A}_{2} \mathrm{~F}$ (5'-AAC TTTAAGAAGGAGATATAATGAACGTTCGGCTGTCTGATGTAG-3') and SrfAB-A R (5'-CAGTGGTGGTGGTGGTGGTGGGCCAAGGCCTTGCCTCC $-3)$. The DNA fragment was inserted into pET21b (NdeI and XhoI digested) using $\mathrm{HiFi}$ assembly (New England Biolabs), generating construct pET21b-srfAB- $\mathrm{A}_{2}$, and used to transform E. coli BL21 for protein production.

For production of recombinant proteins (MloA, MloI $\mathrm{A}_{2} \mathrm{~T}_{2}$ and SrfAB $\mathrm{A}_{2}$ ), a single BL21 colony was used to inoculate an LB seed culture containing ampicillin $\left(50 \mu \mathrm{g} \mathrm{ml}^{-1}\right)$ and cultivated at $37^{\circ} \mathrm{C}$ overnight, before dilution 100 fold into fresh LB supplemented with ampicillin $\left(50 \mu \mathrm{g} \mathrm{ml}^{-1}\right)$. Cultures were incubated at $37^{\circ} \mathrm{C}$ until an $\mathrm{OD}_{600}$ of 0.6 was reached, whereupon isopropyl $\beta$ -D-1-thiogalactopyranoside $(0.5 \mathrm{mM})$ was added to induce protein production. The cultures were cultivated for a further $4 \mathrm{~h}$ at $30^{\circ} \mathrm{C}$ before the cells were harvested by centrifugation ( $4000 \mathrm{~g}$ for $10 \mathrm{~min}$ ). The cell pellets were resuspended in lysis buffer (50 mM Tris pH 8.0,300 $\mathrm{mM} \mathrm{NaCl}$ and $10 \%$ glycerol) and lysed by sonication (Bandelin Sonopuls; $50 \%$ power, $30 \%$ cycle, $8 \mathrm{~min}$ ). Lysates were clarified by centrifugation $(10,000 \mathrm{~g})$. The supernatants were loaded over Ni-NTA columns and washed with 5 column volumes of wash buffer $1(50 \mathrm{mM}$ Tris $\mathrm{pH} 8.0,300 \mathrm{mM} \mathrm{NaCl}, 20 \mathrm{mM}$ imidazole and $10 \%$ glycerol) and 3 column volumes wash buffer 2 ( $50 \mathrm{mM}$ Tris $\mathrm{pH} 8.0,300 \mathrm{mM} \mathrm{NaCl}, 60 \mathrm{mM}$ imidazole and $10 \%$ glycerol), and the protein was eluted with 5 column volumes of elution buffer (50 mM Tris pH 8.0, $300 \mathrm{mM} \mathrm{NaCl}, 250 \mathrm{mM}$ imidazole and $10 \%$ glycerol). Protein eluates were analysed by sodium dodecyl sulfate-polyacrylamide gel electrophoresis, buffer exchanged into $50 \mathrm{mM}$ Tris $\mathrm{pH} 8.0,300 \mathrm{mM} \mathrm{NaCl}$ and $10 \%$ glycerol, and stored at $-80^{\circ} \mathrm{C}$

Adenylation domain activity assays. The MloI $\mathrm{A}_{2} \mathrm{~T}_{2}$ didomain was assayed against a range of substrates including the proteinogenic amino acids, $\mathrm{D}$-Asp, $\beta$-Ala and succinic acid. Activity was measured in real time using an EnzChek pyrophosphate (PPi) detection assay (Thermo Fisher Scientific), with assays set up as follows: $5 \mathrm{mM}$ dithiothreitol, $1 \mathrm{mM} \mathrm{ATP,} 10 \mathrm{mM} \mathrm{MgCl}$, $10 \mu \mathrm{M}$ MloI, $1 \mathrm{U} \mathrm{ml}^{-1}$ purine nucleoside phosphorylase, $0.03 \mathrm{U} \mathrm{ml}^{-1}$ inorganic pyrophosphatase, $0.2 \mathrm{mM} 7$-methyl-6-thio-guanosine, $10 \%$ glycerol $v / v, 50 \mathrm{mM}$ Tris $\mathrm{HCl} \mathrm{pH} 7.5$ and $0.1 \mathrm{mM} \mathrm{NaN}_{3}$. Reaction mixtures were set up without amino acid substrates and pre-incubated at $25^{\circ} \mathrm{C}$ for $2 \mathrm{~min}$, whereupon substrate $(1 \mathrm{mM})$ or $\mathrm{H}_{2} \mathrm{O}$ and $\mathrm{PPi}(0.5 \mathrm{mM})$ controls were added and the reaction mixtures were incubated for a further $25 \mathrm{~min}$ with agitation in a Synergy HT microplate reader monitoring the absorbance at $360 \mathrm{~nm}$. Relative rates of PPi release were calculated as $\Delta \mathrm{A}_{360} \mathrm{~min}^{-1}$, and compensated for background absorbance due to enzyme-mediated ATP hydrolysis by subtracting the absorbance of the negative controls $\left(\mathrm{H}_{2} \mathrm{O}\right.$ added in place of the substrate). Assays with MloA and SrfAB $\mathrm{A}_{2}$ were carried out similarly.

${ }^{18} \mathrm{O}$-transfer assays. The L- $\left[1-{ }^{18} \mathrm{O}\right]$-Asp 8 and L- $\left[4-{ }^{18} \mathrm{O}\right]$-Asp 9 isotopomer substrates were generated by hydrolysis of the corresponding methyl esters 6 and 7 with $\mathrm{Na}^{18} \mathrm{OH}$ in $\mathrm{H}_{2}{ }^{18} \mathrm{O}$ (Fig. 3a). The reactions were dried and redissolved to approximately $25 \mathrm{mM}$ in buffer ( $50 \mathrm{mM}$ Tris pH 7.5). Assays with MloI $\mathrm{A}_{2} \mathrm{~T}_{2}$ or SrfAB $\mathrm{A}_{2}$ were carried out as above. For analysis of ${ }^{18} \mathrm{O}$-labelled AMP, reactions were quenched with methanol and centrifuged, and ion-suppressing buffer salts were removed from the reaction mixtures by ion exchange using Phenomenex strata SAX SPE cartridges. Briefly, the supernatants were loaded over SAX SPE cartridges, washed with $\mathrm{H}_{2} \mathrm{O}$ and eluted with $5 \%$ formic acid in $10 \%$ methanol. Reactions were analysed by LC-HRMS and isotopic ratios were calculated by measuring the ion count for each of the isotope peaks for AMP $[\mathrm{M}+\mathrm{H}]^{+}(m / z 348,349$ and 350). For thiolation assays involving the capture of Asp by SNAC, reactions were set up as follows: $50 \mathrm{mM}$ Tris $\mathrm{HCl}$ pH 7.5, $0.1 \mathrm{mM} \mathrm{NaN}_{3}, 10 \mathrm{mM} \mathrm{MgCl}_{2}, 0.5 \mathrm{mM}$ ATP, $10 \%$ glycerol $v / v, 10 \mu \mathrm{M}$ MloI $\mathrm{A}_{2} \mathrm{~T}_{2}$ or SrfAB $\mathrm{A}_{2}, 2 \mathrm{mM}$ L-Asp substrate and $2 \mathrm{mM}$ SNAC. Reactions were incubated at $25^{\circ} \mathrm{C}$ for $30 \mathrm{~min}$, then quenched with an equal volume of methanol. The reactions were then centrifuged and the supernatants were analysed by LC-HRMS.

Reporting Summary. Further information on research design is available in the Nature Research Reporting Summary linked to this article.

\section{Data availability}

The data that support the plots within this paper and other findings of this study are available from the corresponding author upon reasonable request. Nucleotide sequences for the malonomycin BGCs are deposited in GenBank (accession numbers MH104948 (S. rimosus paramyceticus R2374) and MH104947 (S. rimosus paromomycinus NRRL 2455). The whole genome shotgun sequence for N. gamkensis NBRC 108242, used for the identification of the malonomycinlike cluster from this strain, was obtained from GenBank National Center for Biotechnology Information reference sequence NZ_BDBM01000044.1. Details on nucleotide sequences and proposed annotations are detailed in the Supplementary Information. 
Received: 4 May 2018; Accepted: 18 October 2018;

\section{Received: 4 May $2018 ;$ Accepted: 18}

\section{References}

1. Batelaan, J. G., Barnick, J. W. F. K., van der Baan, J. L. \& Bickelhaupt, F. The structure of the antibiotic K16. I. The dipeptide side chain. Tetrahedron Lett. 13, 3103-3106 (1972).

2. Batelaan, J. G., Barnick, J. W. F. K., van der Baan, J. L. \& Bickelhaupt, F. The structure of the antibiotic K16. II. Chromophore and total structure. Tetrahedron Lett. 13, 3107-3110 (1972)

3. Schipper, D., van der Baan, J. L. \& Bickelhaupt, F. Biosynthesis of malonomicin. Part $1 .{ }^{13} \mathrm{C}$ nuclear magnetic resonance spectrum and feeding experiments with ${ }^{13} \mathrm{C}$-labelled precursors. J. Chem. Soc. Perkin Trans. 1, 2017-2022 (1979)

4. Chan, Y. A., Podevels, A. M., Kevany, B. M. \& Thomas, M. G. Biosynthesis of polyketide synthase extender units. Nat. Prod. Rep. 26, 90-114 (2009).

5. Stenflo, J., Fernlund, P., Egan, W. \& Roepstorff, P. Vitamin K dependent modifications of glutamic acid residues in prothrombin. Proc. Natl Acad. Sci. USA 71, 2730-2733 (1974).

6. Esmon, C. T., Sadowski, J. A. \& Suttie, J. W. A new carboxylation reaction. J. Biol. Chem. 250, 4744-4748 (1975).

7. Wu, S.-M., Morris, D. P. \& Stafford, D. W. Identification and purification to near homogeneity of the vitamin K-dependent carboxylase. Proc. Natl Acad. Sci. USA 88, 2236-2240 (1991).

8. Wu, S.-M., Cheung, W.-F., Frazier, D. \& Stafford, D. W. Cloning and expression of the cDNA for human gamma-glutamyl carboxylase. Science 254, 1634-1636 (1991)

9. Dowd, P., Ham, S. W. \& Geib, S. J. Mechanism of action of vitamin K. J. Am. Chem. Soc. 113, 7734-7743 (1991).

10. Dowd, P., Ham, S. W. \& Hershline, R. Role of oxygen in the vitamin $\mathrm{K}$-dependent carboxylation reaction: incorporation of a second atom of ${ }^{18} \mathrm{O}$ from molecular oxygen $-{ }^{18} \mathrm{O}_{2}$ into vitamin $\mathrm{K}$ oxide during carboxylase activity. J. Am. Chem. Soc. 114, 7613-7617 (1992)

11. Dowd, P., Hershline, R., Ham, S. W. \& Naganathan, S. Vitamin K and energy transduction: a base strength amplification mechanism. Science $\mathbf{2 6 9}$ 1684-1691 (1995)

12. Fasco, M. J., Preusch, P. C., Hildebrandt, E. \& Suttie, J. W. Formation of hydroxyvitamin $\mathrm{K}$ by vitamin $\mathrm{K}$ epoxide reductase of warfarin-resistant rats. J. Biol. Chem. 258, 4372-4380 (1983).

13. Bell, R. G. \& Matschiner, J. T. Warfarin and the inhibition of vitamin K activity by an oxide metabolite. Nature 237, 32-33 (1972).

14. Rishavy, M. A. et al. The vitamin K-dependent carboxylase has been acquired by Leptospira pathogens and shows altered activity that suggests a role other than protein carboxylation. J. Biol. Chem. 280, 34870-34877 (2005).

15. Kobylarz, M. J. et al. Synthesis of L-2,3-diaminopropionic acid, a siderophore and antibiotic precursor. Chem. Biol. 21, 379-388 (2014).

16. Rishavy, M. A. et al. Brønsted analysis reveals Lys 218 as the carboxylase active site base that deprotonates vitamin $\mathrm{K}$ hydroquinone to initiate vitamin K-dependent protein carboxylation. Biochemistry 45, 13239-13248 (2006)

17. Rishavy, M. A. \& Berkner, K. L. Insight into the coupling mechanism of the vitamin K-dependent carboxylase: mutation of histidine 160 disrupts glutamic acid carbanion formation and efficient coupling of vitamin $\mathrm{K}$ epoxidation to glutamic acid carboxylation. Biochemistry 47, 9836-9846 (2008)

18. Alderson, G., Goodfellow, M. \& Minnikin, D. E. Menaquinone composition in the classification of Streptomyces and other sporoactinomycetes. Microbiology 131, 1671-1679 (1985).

19. Hiratsuka, T. et al. An alternative menaquinone biosynthetic pathway operating in microorganisms. Science 321, 1670-1673 (2008).

20. Nowicka, B. \& Kruk, J. Occurrence, biosynthesis and function of isoprenoid quinones. Biochim. Biophys. Acta 1797, 1587-1605 (2010).

21. Schultz, J. HTTM, a horizontally transferred transmembrane domain. Trends Biochem. Sci. 29, 4-7 (2004).

22. Cobb, R. E., Wang, Y. \& Zhao, H. High-efficiency multiplex genome editing of Streptomyces species using an engineered CRISPR/Cas system. ACS Synth. Biol. 4, 723-728 (2015)

23. Davidsen, J. M., Bartley, D. M. \& Townsend, C. A. Nonribosomal propeptide precursor in nocardicin A biosynthesis predicted from adenylation domain specificity dependent on the MbtH family protein NocI. J. Am. Chem. Soc. 135, 1749-1759 (2013).
24. Reimer, D., Pos, K. M., Thines, M., Grün, P. \& Bode, H. B. A natural prodrug activation mechanism in nonribosomal peptide synthesis. Nat. Chem. Biol. 7, 888-890 (2011)

25. Luo, Y. et al. Validation of the intact zwittermicin A biosynthetic gene cluster and discovery of a complementary resistance mechanism in Bacillus thuringiensis. Antimicrob. Agents Chemother. 55, 4161-4169 (2011).

26. Marahiel, M. A., Stachelhaus, T. \& Mootz, H. D. Modular peptide synthetases involved in nonribosomal peptide synthesis. Chem. Rev. 97, 2651-2673 (1997).

27. Bergendahl, V., Linne, U. \& Marahiel, M. A. Mutational analysis of the C-domain in nonribosomal peptide synthesis. Eur. J. Biochem. 269, 620-629 (2002)

28. Webb, M. R. A continuous spectrophotometric assay for inorganic phosphate and for measuring phosphate release kinetics in biological systems. Proc. Natl Acad. Sci. USA 89, 4884-4887 (1992).

29. Pavela-Vrancic, M., Dieckmann, R. \& Von Döhren, H. ATPase activity of non-ribosomal peptide synthetases. Biochim. Biophys. Acta 1696, 83-91 (2004).

30. Stachelhaus, T., Mootz, H. D. \& Marahiel, M. A. The specificity-conferring code of adenylation domains in nonribosomal peptide synthetases. Chem. Biol. 6, 493-505 (1999).

31. Szókán, G., Mezö, G. \& Hudecz, F. Application of Marfey’s reagent in racemization studies of amino acids and peptides. J. Chromatogr. 444, 115-122 (1988).

32. Bochmann, S. M., Spieß, T., Kötter, P. \& Entian, K. D. Synthesis and succinylation of subtilin-like lantibiotics are strongly influenced by glucose and transition state regulator AbrB. Appl. Environ. Microbiol. 81, 614-622 (2015).

33. Cochrane, S. A., Surgenor, R. R., Khey, K. M. W. \& Vederas, J. C. Total synthesis and stereochemical assignment of the antimicrobial lipopeptide cerexin A1. Org. Lett. 17, 5428-5431 (2015).

34. Spieß, T., Korn, S. M., Kötter, P. \& Entian, K. D. Activation of histidine kinase SpaK is mediated by the N-terminal portion of subtilin-like lantibiotics and is independent of lipid II. Appl. Environ. Microbiol. 81, 5335-5343 (2015)

35. Chan, W. C., Bycroft, B. W., Leyland, M. L., Lian, L.-Y. \& Roberts, G. C. K. A novel post-translational modification of the peptide antibiotic subtilin: isolation and characterization of a natural variant from Bacillus subtilis A.T.C.C. 6633. Biochem. J. 291, 23-27 (1993).

36. Altschul, S. F. et al. Gapped BLAST and PSI-BLAST: a new generation of protein database search programs. Nucleic Acids Res. 25, 3389-3402 (1997)

37. Rutherford, K. et al. Artemis: sequence visualization and annotation. Bioinformatics 16, 944-945 (2000).

\section{Acknowledgements}

We thank BBSRC (grant BB/K002341/1) and Syngenta for funding. The SYNBIOCHEM Centre (grant BB/M017702/1) and Michael Barber Centre for Mass Spectrometry at the University of Manchester provided access to mass spectrometry instrumentation. J. Vincent and N. Mulholland (Syngenta) are also acknowledged for helpful discussion.

\section{Author contributions}

B.J.C.L., Y. Zhuo, M.W. and J.M. designed the experiments. B.J.C.L., Y.Z., M.W., D.F, Y. Zhang, A.M. and L.R. carried out the experiments. M.S. and P.F.L. sequenced and annotated the genomes. B.J.C.L. and J.M. wrote the manuscript. All authors analysed the data and reviewed the manuscript.

\section{Competing interests}

The authors declare no competing interests.

\section{Additional information}

Supplementary information is available for this paper at https://doi.org/10.1038/ s41929-018-0178-2

Reprints and permissions information is available at www.nature.com/reprints. Correspondence and requests for materials should be addressed to J.M.

Publisher's note: Springer Nature remains neutral with regard to jurisdictional claims in published maps and institutional affiliations.

(c) The Author(s), under exclusive licence to Springer Nature Limited 2018 


\section{QUERY FORM}

\section{Nature Catalysis}

\begin{tabular}{|l|c|}
\hline Manuscript ID & [Art. Id: 178] \\
\hline Author & Brian J. C. Law \\
\hline
\end{tabular}

\section{AUTHOR:}

The following queries have arisen during the editing of your manuscript. Please answer by making the requisite corrections directly in the e.proofing tool rather than marking them up on the PDF. This will ensure that your corrections are incorporated accurately and that your paper is published as quickly as possible.

\begin{tabular}{|c|c|}
\hline Query No. & Nature of Query \\
\hline Q1: & $\begin{array}{l}\text { In the e.proof tool, the numbers for those compounds that will be deposited in PubChem do not appear bold, } \\
\text { and the link is not visible. You do not need to amend this, they will appear correctly once published online. }\end{array}$ \\
\hline Q2: & $\begin{array}{l}\text { Please check your article carefully, coordinate with any co-authors and enter all final edits clearly in the eproof, } \\
\text { remembering to save frequently. Once corrections are submitted, we cannot routinely make further changes to } \\
\text { the article. }\end{array}$ \\
\hline Q3: & $\begin{array}{l}\text { Note that the eproof should be amended in only one browser window at any one time; otherwise changes will } \\
\text { be overwritten. }\end{array}$ \\
\hline Q4: & $\begin{array}{l}\text { Author surnames have been highlighted. Please check these carefully and adjust if the first name or surname } \\
\text { is marked up incorrectly. Note that changes here will affect indexing of your article in public repositories such } \\
\text { as PubMed. Also, carefully check the spelling and numbering of all author names and affiliations, and the cor- } \\
\text { responding email address(es). }\end{array}$ \\
\hline Q5: & $\begin{array}{l}\text { Please note that after the paper has been formally accepted you can only provide amended Supplementary } \\
\text { Information files for critical changes to the scientific content, not for style. You should clearly explain what } \\
\text { changes have been made if you do resupply any such files. }\end{array}$ \\
\hline Q6: & $\begin{array}{l}\text { Please check that the definitions in the Fig. } 1 \text { caption are correct and add one for 'SCoA'. Note that anything } \\
\text { already defined in the text does not need to be re-defined in a figure caption. In some instances, acronyms in } \\
\text { the text have been expanded because they weren't used often enough. These then need to be redefined in every } \\
\text { figure caption where the corresponding figure uses them. }\end{array}$ \\
\hline Q7: & $\begin{array}{l}\text { In the sentence 'An mloA S546A mutation was similarly introduced...' please check that PCP has been ex- } \\
\text { panded correctly. }\end{array}$ \\
\hline Q8: & $\begin{array}{l}\text { In the sentence 'In addition, complementation of the } \Delta \text { mloA strain...' 'mloA(S546A)' has 'S546A' in brackets } \\
\text { with no space before. This is inconsistent with the preceding sentence, which uses 'mloA S546A'. Please select } \\
\text { one method of formatting for consistency. }\end{array}$ \\
\hline Q9: & $\begin{array}{l}\text { When referring to carboxyl groups, there is a non-subscript number, but for domains it is subscript. Please } \\
\text { check this is correct. }\end{array}$ \\
\hline Q10: & $\begin{array}{l}\text { In the sentence 'Transfer of the } 18 \mathrm{O} \text { label from the C4 (side-chain)...' please check that the definition of 'AMP' } \\
\text { is correct. }\end{array}$ \\
\hline Q11: & Please provide an expansion for 'std' in Fig. 3c. \\
\hline
\end{tabular}




\section{QUERY FORM}

\begin{tabular}{|l|c|}
\hline \multicolumn{2}{|c|}{ Nature Catalysis } \\
\hline Manuscript ID & [Art. Id: 178] \\
\hline Author & Brian J. C. Law \\
\hline
\end{tabular}

\section{AUTHOR:}

The following queries have arisen during the editing of your manuscript. Please answer by making the requisite corrections directly in the e.proofing tool rather than marking them up on the PDF. This will ensure that your corrections are incorporated accurately and that your paper is published as quickly as possible.

\begin{tabular}{|c|c|}
\hline Query No. & Nature of Query \\
\hline Q12: & In the Fig. $4 \mathrm{~b}$ caption, please check it's correct for 'HPLC' to have been changed to 'RP=HPLC' for consistency. \\
\hline Q13: & $\begin{array}{l}\text { In the sentence 'Efforts to isolate malonomycin-like metabolites...' please check that the spelt-out genus names } \\
\text { are correct. }\end{array}$ \\
\hline Q14: & Twice in the section 'Genome annotation', please check that 'CDSs' has been expanded correctly. \\
\hline Q15: & $\begin{array}{l}\text { In the sentence 'Annotation was transferred by a set of in-house PERL scripts...' please expand KEGG and } \\
\text { check that NR has been expanded correcly. }\end{array}$ \\
\hline Q16: & $\begin{array}{l}\text { In the sentence 'Coding sequences were colour coded according to the hits...' please check that COG has been } \\
\text { expanded correctly. }\end{array}$ \\
\hline Q17: & $\begin{array}{l}\text { In the senetence 'Multiple-stage mass spectrometry analysis...' and the one that follows it, please check that } \\
\mathrm{MS} \wedge^{\wedge} \text { nas been expanded correctly. }\end{array}$ \\
\hline Q18: & $\begin{array}{l}\text { Please check the edits to the sentence 'Fragmentation settings were set as targeted...' retain the intended mean- } \\
\text { ing, and expand CID. }\end{array}$ \\
\hline Q19: & In the sentence 'For NMR analysis, compounds were...' please expand 'DCI'. \\
\hline Q20: & $\begin{array}{l}\text { In the sentence 'The samples were analysed on an Agilent Infinity } 1200 \text { series HPLC...' please check that the } \\
\text { addition of ' } \mathrm{B} \text { ' after ' } 5 \% \text { ' and before ', with mobile phase A...' is correct. }\end{array}$ \\
\hline Q21: & 'orfs' has been changed to 'ORFs' and defined as 'open reading frames' at first mention. Please check this is correct. \\
\hline Q22: & In the sentence 'Exconjugants were picked to SFM agar plates...' please define 'SFM'. \\
\hline Q23: & In the paragraph beginning 'For production of recombinant proteins...' please expand 'LB' at both mentions. \\
\hline Q24: & $\begin{array}{l}\text { In the senetence 'Cultures were incubated at } 37^{\circ} \mathrm{C} \text { until an...' please amend the wording to avoid referring to } \\
\text { the optical density. Per journal style, we use absorbance instead. }\end{array}$ \\
\hline Q25: & In the sentence 'Cultures were incubated at $37^{\circ} \mathrm{C}$ until...' please check that 'IPTG' has been expanded correctly. \\
\hline Q26: & $\begin{array}{l}\text { In the sentence 'Activity was measured in real time using an EnzChek...' and the Fig. } 3 \text { caption, please check } \\
\text { that MESG has been expanded correctly. }\end{array}$ \\
\hline Q27: & $\begin{array}{l}\text { pyrophosphate has been defined as 'PPi' at first mention in the text, and then written as PPi elsewhere. Please } \\
\text { check this is formatted correctly, as the original Fig. } 3 \text { legend used a subscript and italic 'i'. }\end{array}$ \\
\hline
\end{tabular}




\section{QUERY FORM}

\section{Nature Catalysis}

\section{Manuscript ID}

Author
[Art. Id: 178]

\author{
Brian J. C. Law
}

\section{AUTHOR:}

The following queries have arisen during the editing of your manuscript. Please answer by making the requisite corrections directly in the e.proofing tool rather than marking them up on the PDF. This will ensure that your corrections are incorporated accurately and that your paper is published as quickly as possible.

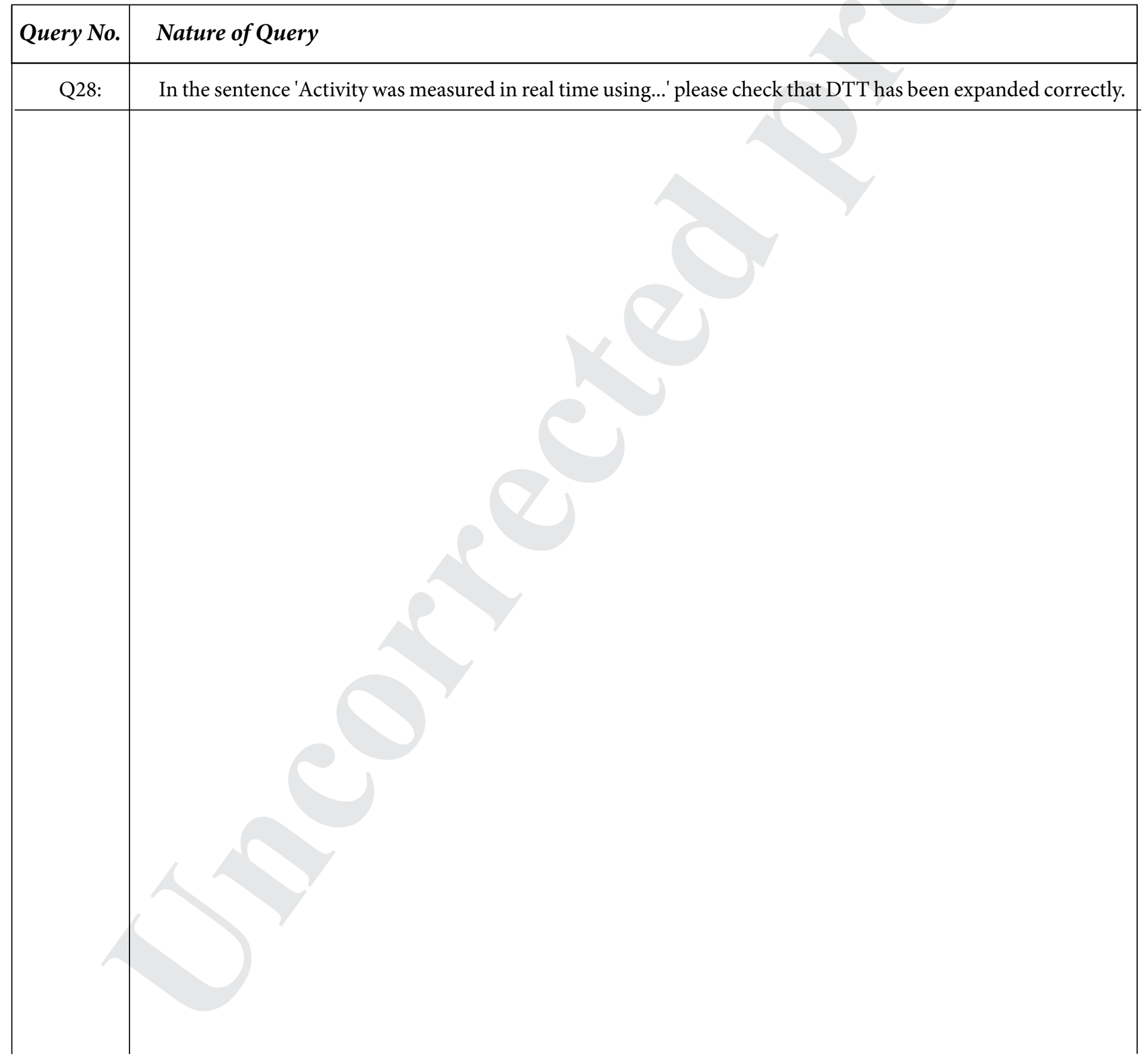




\section{Reporting Summary}

Nature Research wishes to improve the reproducibility of the work that we publish. This form provides structure for consistency and transparency in reporting. For further information on Nature Research policies, see Authors \& Referees and the Editorial Policy Checklist.

\section{Statistical parameters}

When statistical analyses are reported, confirm that the following items are present in the relevant location (e.g. figure legend, table legend, main text, or Methods section).

n/a Confirmed

$\bigotimes$ The exact sample size $(n)$ for each experimental group/condition, given as a discrete number and unit of measurement

$\square$ An indication of whether measurements were taken from distinct samples or whether the same sample was measured repeatedly

$\square$ The statistical test(s) used AND whether they are one- or two-sided

$\triangle$ Only common tests should be described solely by name; describe more complex techniques in the Methods section.

Х A description of all covariates tested

$\square$ \ A description of any assumptions or corrections, such as tests of normality and adjustment for multiple comparisons

$\triangle$ A full description of the statistics including central tendency (e.g. means) or other basic estimates (e.g. regression coefficient) AND

X $\square$ variation (e.g. standard deviation) or associated estimates of uncertainty (e.g. confidence intervals)

$\triangle$ For null hypothesis testing, the test statistic (e.g. $F, t, r$ ) with confidence intervals, effect sizes, degrees of freedom and $P$ value noted

$\bigotimes \square$ Give $P$ values as exact values whenever suitable.

Х $\square$ For Bayesian analysis, information on the choice of priors and Markov chain Monte Carlo settings

Х $\square$ For hierarchical and complex designs, identification of the appropriate level for tests and full reporting of outcomes

Х $\square$ Estimates of effect sizes (e.g. Cohen's $d$, Pearson's $r$ ), indicating how they were calculated

$\varnothing$ Clearly defined error bars

$\triangle$ State explicitly what error bars represent (e.g. SD, SE, CI)

Our web collection on statistics for biologists may be useful.

\section{Software and code}

Policy information about availability of computer code

Data collection Thermo Xcalibur v2.2 (mass spectrometry), Agilent ChemStation (HPLC), Shimadzu LabSolutions Lite v5 (HPLC), BioTek Gen5 v2 (96-well plate reader spectrophotometer), FLASH v1.2.11, Newbler v3 (nucleotide sequencing)

Data analysis Thermo Xcalibur v2.2 (mass spectrometry), Agilent ChemStation (HPLC), Shimadzu LabSolutions Lite v5 (HPLC), BioTek Gen5 v2 (96-well plate reader spectrophotometer), antiSMASH v3.0.5 and Artemis v16 (gene cluster analysis), fgeneSB v2 (genome annotation), Clustal OMEGA, T Coffee, Mega7 (sequence alignments and phylogeny), MestReNova v11 (NMR), ChemDraw Professional v15 (chemical structures and exact mass calculations)

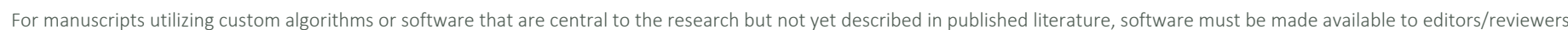

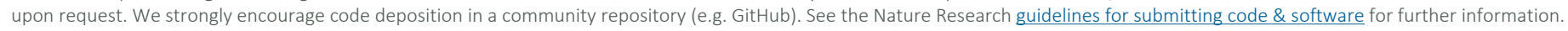


Policy information about availability of data

All manuscripts must include a data availability statement. This statement should provide the following information, where applicable:

- Accession codes, unique identifiers, or web links for publicly available datasets

- A list of figures that have associated raw data

- A description of any restrictions on data availability

Nucleotide sequences for the malonomycin biosynthetic gene clusters are deposited in GenBank; accession numbers MH104948 (Streptomyces rimosus paramyceticus R2374) and MH104947 (Streptomyces rimosus paromomycinus NRRL 2455). All data are included in the manuscript or in the supplementary information. The whole genome shotgun sequence for Nocardia gamkensis NBRC 108242, used for the identification of the malonomycin-like cluster from this strain, was obtained from GenBank NCBI reference sequence: NZ_BDBM01000044.1. Details on individual nucleotide sequences and proposed annotation are detailed in the supplementary.

\section{Field-specific reporting}

Please select the best fit for your research. If you are not sure, read the appropriate sections before making your selection.

$\bigotimes$ Life sciences $\quad \square$ Behavioural \& social sciences $\quad \square$ Ecological, evolutionary \& environmental sciences

For a reference copy of the document with all sections, see nature.com/authors/policies/Reportingsummary-flat.pdf

\section{Life sciences study design}

All studies must disclose on these points even when the disclosure is negative.

Sample size For mutant bacterial colonies, replicates with the same genotype were shown to behave consistently with each other. Details are included within the text.

Data exclusions No data were excluded

Replication Replication was carried out in at least triplicate, in separate experiments, all replicates were successful.

Randomization n/a (no randomization, this study does not involve animal or human subjects or group allocation)

Blinding n/a (no blinding, this study does not involve animal or human subjects or group allocation)

\section{Reporting for specific materials, systems and methods}

Materials \& experimental systems

$\mathrm{n} / \mathrm{a}$ Involved in the study

$\searrow \square$ Unique biological materials

Х $\square$ Antibodies

Х Eukaryotic cell lines

Х $\square$ Palaeontology

$\square$ Animals and other organisms

$\bigotimes \mid \square$ Human research participants

\begin{tabular}{l|l} 
Methods \\
\hline n/a Involved in the study \\
$\square \square$ ChIP-seq \\
$\square$ Flow cytometry \\
$\square$ MRI-based neuroimaging
\end{tabular}

Animals and other organisms

Policy information about studies involving animals; ARRIVE guidelines recommended for reporting animal research

Laboratory animals

Wild animals

Field-collected samples the study did not involve laboratory animals

the study did not involve wild animals

the study did not involve samples collected from the field 